\title{
Tooth Fragment Reattachment with Glass Fiber Reinforced Post: A Case Report
}

\author{
Med Salah Ameur ${ }^{1}$ Ines Kallel ${ }^{2,3}$ Fadwa Chtioui $^{2}$ Nabiha Douki ${ }^{2,3}$
}

\author{
'Department of Endodontics and Conservative Odontology, Faculty of \\ Dental Medicine, University of Monastir, Monastir, Tunisia \\ ${ }^{2}$ Department of Endodontics and Conservative Odontology, Faculty of \\ Dental Medicine, EPS Sahloul, Sousse, Tunisia \\ ${ }^{3}$ Research Laboratory LR12ES11, Faculty of Dental Medicine, University \\ of Monastir, Monastir, Tunisia
}

\begin{abstract}
Address for correspondence: Med Salah Ameur, Department of Endodontics and Conservative Odontology, Faculty of Dental Medicine, University of Monastir, Avenue Avicenne, 5019 Monastir, Tunisia E-mail: medsalahdentiste@gmail.com
\end{abstract}

\begin{abstract}
This case report presents the treatment a 15-year-old child referred to our dental department $24 \mathrm{~h}$ following a dental trauma during sports activities resulting in a coronal fracture of tooth \#11. After clinical and radiographic examination, a crown fracture with pulp exposure was noticed. The operating field was isolated with a rubber dam to ensure moisture control and an endodontic treatment was performed. In the second visit, the root canal filling material was partially removed while maintaining 5 $\mathrm{mm}$ in the apical third. A dual resin was injected into the canal from the apical to the coronal third. The fiber post was placed into the root. Then, the fractured fragment was placed on the root with the fiber post passing through the access cavity into the crown. In the third visit (one month later), a $3 \mathrm{~mm}$-deep preparation was performed in the buccal surface using a round diamond bur. Following color matching, a fluid composite was applied on the buccal preparation and it was light-cured. This was followed by finishing and polishing.
\end{abstract}

Keywords: Adhesive dental materials, dental trauma, fiber post, resin composite, tooth fractures

\section{Introduction}

Crown fractures are commonly caused by injuries such as sports activities, aggression, and road traffic accidents. They can be simple or complicated enamel-dentin fractures. Over time, numerous techniques and materials have evolved for the reconstruction of fractured teeth, including resin, steel, ceramic crowns, and resin composite restorations with and without post. Selection of the restorative technique is not a simple decision and it represents a great clinical challenge. The patient's age, the extension of the crown fracture, the presence of direct pulp exposure, the stage of radicular development, and the type of occlusion must be taken into account in order to choose the best treatment for each patient. [1-4] Other factors are also crucial in the process of choosing the right treatment alternative at the moment of the fracture. Indeed, treatment must be esthetic, simple, and conservative. It should as well have a low cost.

With the advent of adhesive dentistry, the process of fragment reattachment has become simplified and more reliable. This technique can be considered as the most functional, conservative, and esthetic treatment modality for crown fractures. [5,6]

How to cite this article: Ameur MS, Kallel I, Chtioui F, Douki N. Tooth Fragment Reattachment with Glass Fiber Reinforced Post: A Case Report. J Pediatr Dent 2021;7(1):00-00 
The crown fracture extension often requires the use of a post to achieve the retention form and to protect the bond form twisting forces. [7]

Nowadays, fiber posts can offer resistance, good esthetic outcomes, a good ability to bonding and strength, a modulus of elasticity close to that of the dentin, and decreased chances of fracture.[8]

In this article, a case of fragment reattachment with a glass fiber post is presented and described. The advantages of this treatment modality are also exposed and compared to resin restoration. Finally, the different settings to ensure a good treatment respecting adhesive dentistry are discussed.

\section{Case Presentation}

A 15-year-old child presented to our dental department $24 \mathrm{~h}$ following a dental trauma during sports activities resulting in a coronal fracture of tooth \#11. The fractured fragment was brought by the patient in a dry paper with an elapsed time of over one hour. After clinical and radiographic examination, a crown fracture with pulp exposure was noticed (Fig. 1). Once diagnosis was made, the treatment options were presented to the patient, including post core and crown, build-up restoration using resin-based composite, and reattachment of the dental fragment.

Consent of the patient's mother was obtained following a discussion of the advantages, the drawbacks, the prognosis, and the cost of every treatment option. Fragment reattachment was the final decision. The option of fragment reattachment was considered only after verifying that the fragment was in good condition and it fitted well on the fractured tooth.

The operating field was isolated with a rubber dam to ensure moisture control and an endodontic treatment was performed.

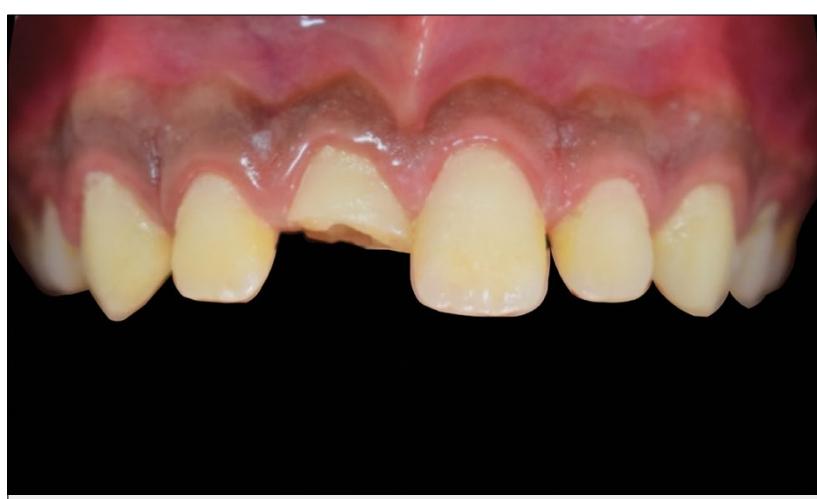

Figure 1. Preoperative view of the maxillary right central incisor with a complicated crown fracture
In the second visit, the root canal filling material was partially removed while maintaining $5 \mathrm{~mm}$ in the apical third. The length of the fiber post was then measured using a periodontal probe (Fig. 2). Preparation of the dentin groove in the fragment was carefully carried out using a round bur corresponding to the length and the diameter of the fiber post (Fig. 3).

After etching the root canal of the fractured tooth for 15 s with $37 \%$ orthophosphoric acid gel (Fig. $4 a$ ), it was rinsed, dried, and then filled with adhesive (Fig. 4b). Acid etching was also applied on the fragment for $15 \mathrm{~s}$, and then it was thoroughly rinsed (Fig. 4c). The fragment was kept moist and excess water was removed using paper. Then, the adhesive was applied on the fractured fragment (Fig. 4d). The glass fiber post was also covered with adhesive resin and it was polymerized (Fig. 4e).

A dual resin was injected into the canal from the apical to the coronal third. The fiber post was placed into the root. Then, the fractured fragment was placed on the root with the fiber post passing through the access cavity into the crown (Fig. 5).

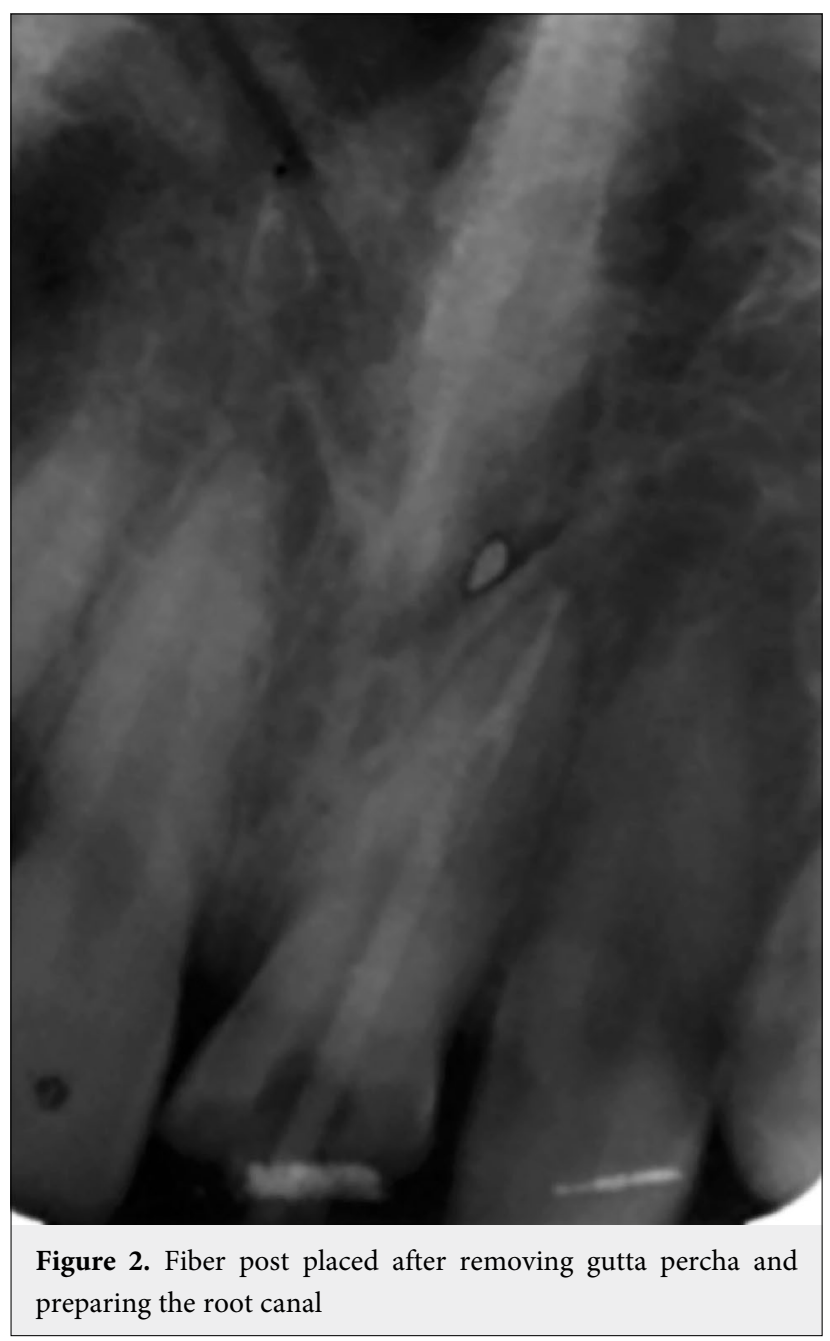




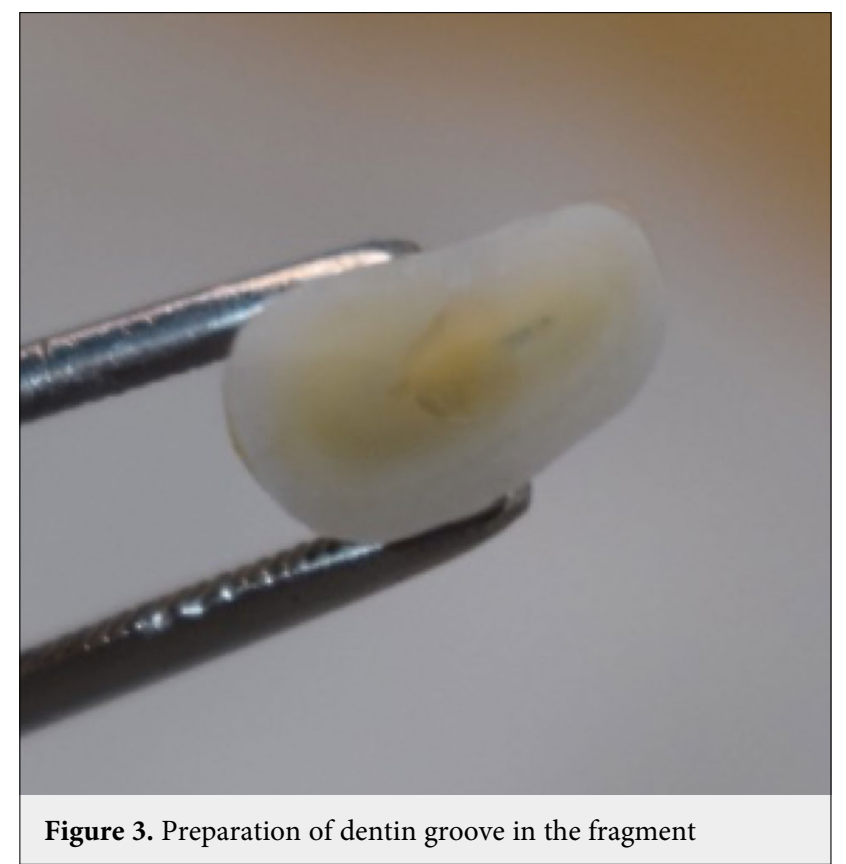

The fit of the fractured crown piece to the root was evaluated. Later, excess resin cement was removed and then light-cured (Fig. 6). Occlusion was carefully checked to avoid any primary contacts or traumatic occlusal forces to the restored tooth.

In the third visit (one month later), in order to improve the transition line between the crown and the fractured fragment, a $3 \mathrm{~mm}$-deep preparation was performed in the buccal surface using a round diamond bur. Hence, the preparation was extended $2 \mathrm{~mm}$ on both sides of the fracture line.

Following color matching, a fluid composite was applied on the buccal preparation and it was light-cured. This was followed by finishing and polishing (Fig. 7).

\section{Discussion}

When the fragment is available at the site of the accident, the first treatment choice of coronal fractures is immediate fragment reattachment. This technique has become more and more appealing thanks to the presence of new dentin bonding agents. Yet, some clinical factors should be considered before performing this procedure;

The crown fracture extension: when the biological width is involved, it should be reestablished by a periodontal surgery to achieve a clinical-crown prognosis and to provide tooth reattachment.

Intact fragment with good adaptation: the texture of the fragment should also be also verified because even a crack can compromise prognosis.

Keeping the fragment in a suitable storage: Ideally, the fragment should be placed in a hydrated storage
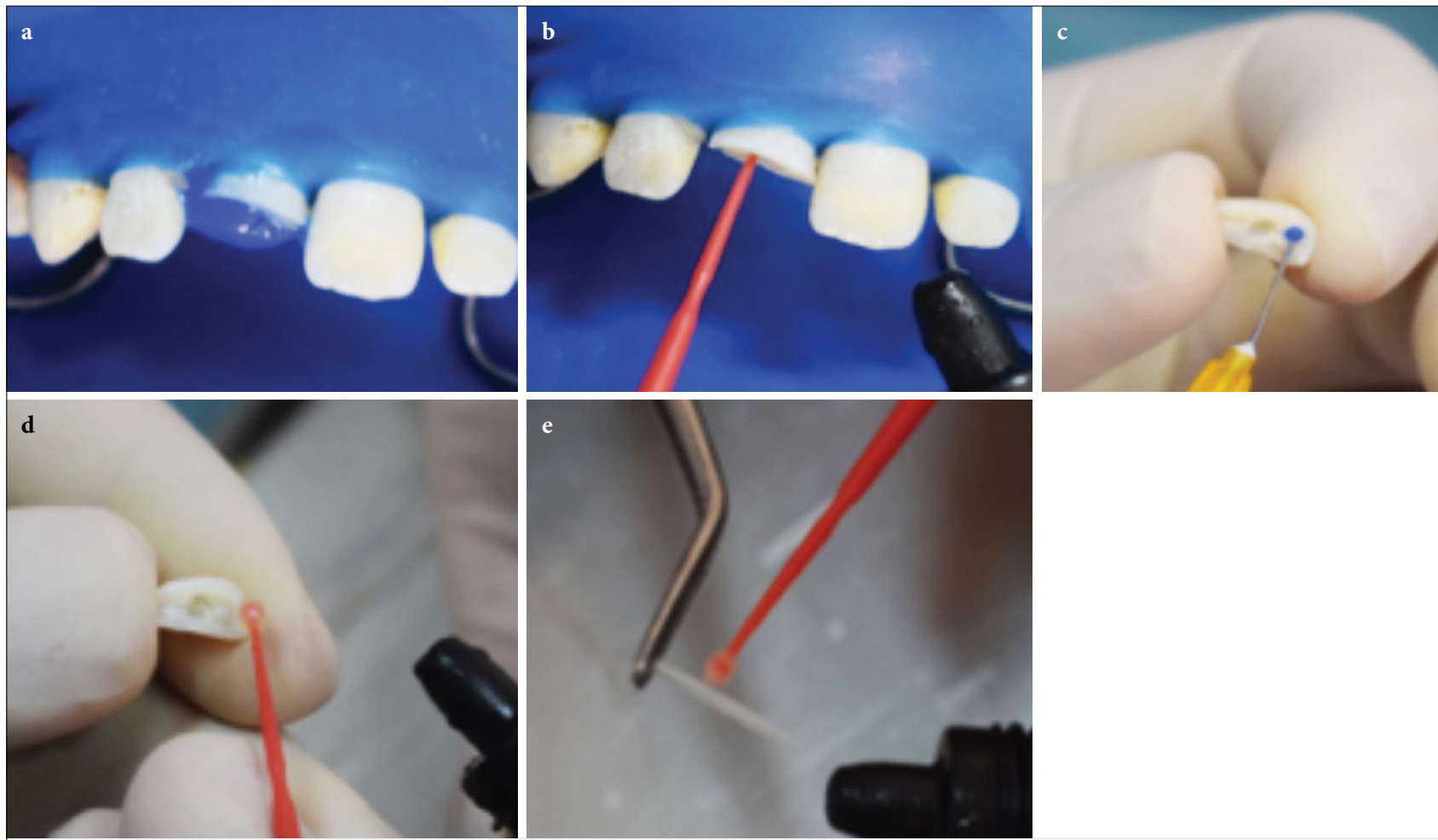

Figure 4. (a) Acid etching of the root canal and the tooth, (b) Application of adhesive in the root canal and the tooth, (c) Acid etching of fractured fragment, (d) Application of adhesive on fractured fragment, (e) Application of adhesive on the fiber post 


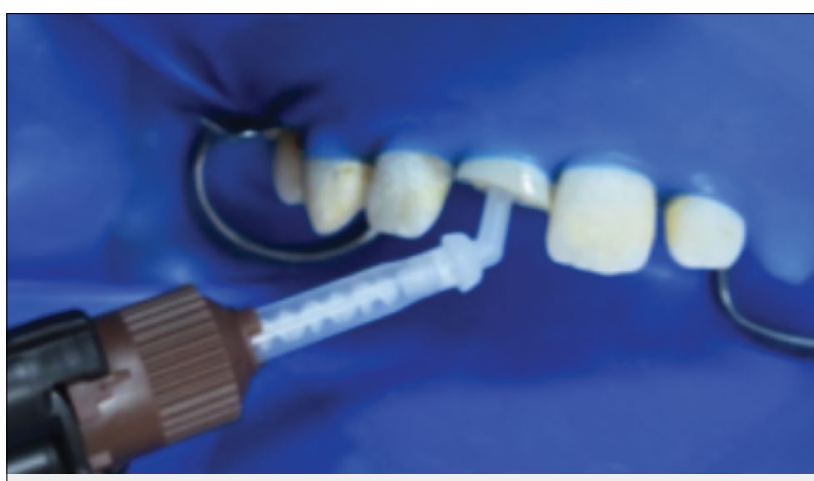

Figure 5. Injection of dual resin in the root canal and in the fracture line
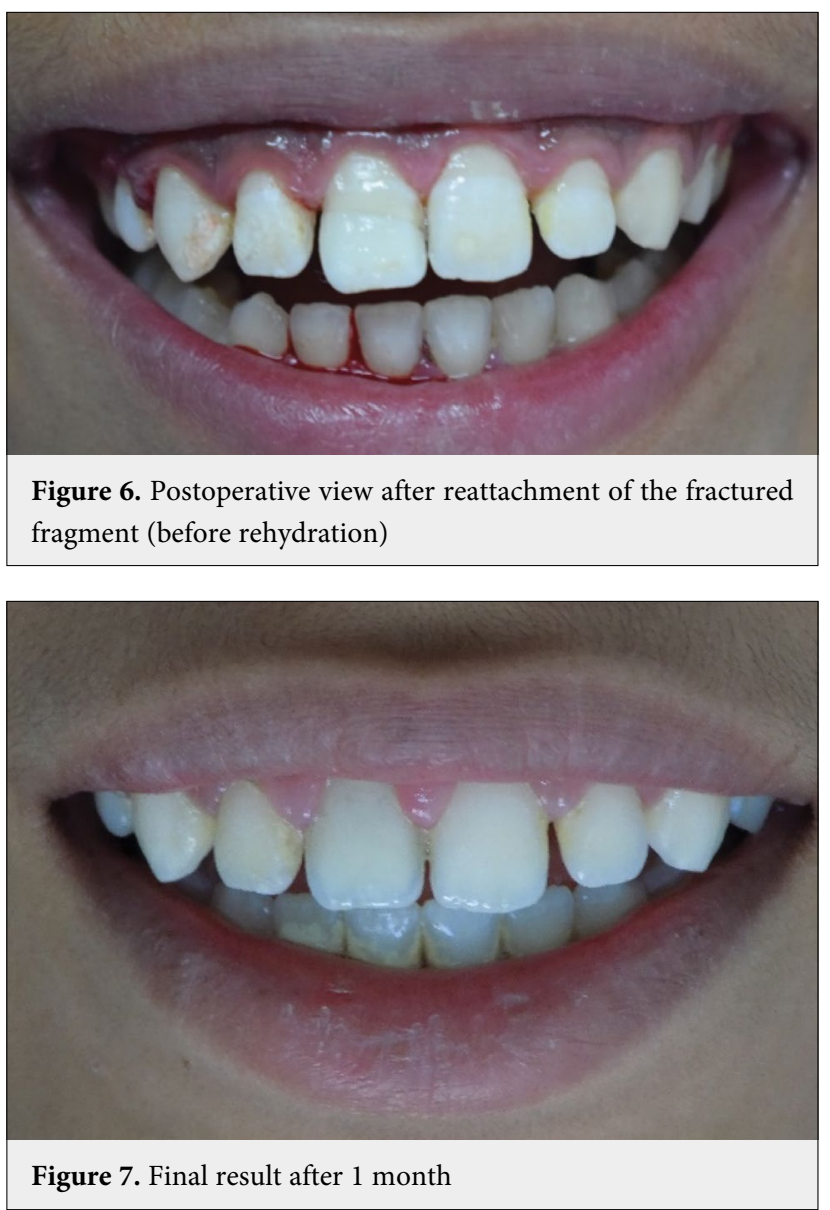

(water, saliva, physiologic solution) to avoid discoloration and dehydration. However, many studies have shown that the use of a dehydrated tooth fragment does not achieve the desirable esthetic effect. It will therefore be less than ideal, and the fragment can regain its normal coloration after only two weeks. $[1,3,5,9,10]$

Compared to resin restoration, fragment reattachment can be considered as the most functional, conservative and esthetic treatment modality for crown fractures of maxillary incisors.[1,2,11] It has various advantages, including psychological ones, treatment rapidity, reproducing exact morphology and texture, and providing immediate esthetics. It also provides color match to the remnant crown, preserves incisal translucency and tooth contours, and delays "prosthetic restoration" for young patients.[12]

However, Composite-resin build-up presents a major challenge to clinicians when reestablishing esthetics, shade, form, dimensions, opacity, and translucency of the fractured tooth. Frequently, composite restoration presents difficulties in matching color and it shows higher wear than the enamel structure. Nowadays, with the latest development in adhesive systems and composite-resin materials, greater longevity of composite resin build-up restoration is expected. Failure may be due to several reasons, such as bond failure, marginal failure, discoloration, composite fracture, and shade instability. Taking the aforementioned reasons into account and after validation of the conditions cited above, we opted for fragment reattachment in the present case.[5]

For our patient, to ensure good retention and to protect the fragment and bond from the twisting forces, using a post was necessary. Therefore, the integrity in the final endodontic restorative continuum was close to the one in the original healthy tooth.[13]

The choice of using a fiber post can be justified by its ability to offer high resistance, good esthetic outcomes, good ability to bond, and its ability to provide a modulus of elasticity near to that of the dentin and reduced chances of fracture. Moreover, fiber posts help to distribute stress to the remaining radicular dentin.[14-16]

In the light of many published studies, it has become evident that the restoration strength of fractured teeth depends on the preparation technique and the material used to bond the fractured fragment.[17]

Canal preparation is a very important step in order to receive the fiber post. In fact, if the post is shorter than the coronal height of the clinical crown, prognosis is considered unfavorable because stress is distributed over a smaller surface area.[8] As the length of the post increases, retention increases simultaneously.[18] Most endodontic literature recommends maintaining a 5 $\mathrm{mm}$-apical seal, while $3 \mathrm{~mm}$ is considered the absolute minimum.

To increase retention of the reattached fragment, preparation methods, including enamel leveling of the fragment and the remaining crown, internal dentin groove, external chamfer, and the over-contour technique have been described. All of these methods have their advantages and disadvantages.[1,19-21]

In simple reattachment, fragments are restored without an additional preparation. The fragments are reat- 
tached using bonding agents only. The internal groove technique consists in preparing a groove within the fragment and the remaining tooth before reattachment.

The over-contour technique consists in performing a $0.3 \mathrm{~mm}$-deep preparation in the buccal fracture line using a round diamond bur. Then, the preparation is extended $2.5 \mathrm{~mm}$ coronally and apically. To restore the buccal preparation, resin composite is used, and it is followed by light curing, finishing, and polishing. In this case, we opted for this technique to minimize the loss of dentin substance. As the place of the fiber was already prepared, an additional preparation can weaken the tooth.

Studies have shown that the highest fracture strength recovery is obtained with the internal dentin groove technique, followed by the over-contour and the simple reattachment techniques. $[5,22,23]$ In the simple reattachment groups, the fracture strength recovery values are significantly increased by the use of resin composite compared to using bonding agents only.

In terms of retention, the clinical outcome of tooth fragment reattachment still depends on the enamel bonding. [24] In those cases, adhesive systems that use phosphoric acid as a separate conditioner still represent the golden standard despite the advantages of the selfetching system.[5]

Many studies have discouraged the use of self-etching adhesives on intact enamel because of greater microleakage, lower bond strength, and shallow etching patterns that prevent good penetration of the bonding resin.

Therefore, to avoid these problems, an additional preceding etching step of the enamel with phosphoric acid, especially in case of non-instrumented enamel, is recommended to increase the bond strength. $[5,8,25]$

The fracture line must be far from the occlusal contact. In fact, the twisting forces can affect retention and destabilize the fragment. Thus, when contact with the antagonist tooth is located in the fracture line, we can often edit the lingual surface of the crown or in some cases reduce the mandibular incisor.[26]

Finally, to ensure the restoration longevity, the fiber length in the root must be superior to that in the crown. The part exceeding the root should therefore be totally exploited to penetrate the fragment while keeping it away from occlusal stress.[12]

\section{Conclusion}

Several aspects govern the choice of the appropriate technique or the association of materials for fragment reattachment. Fragment reattachment with fiber post proved to be a successful technique in the immediate restoration of function and esthetics in the present case.

Financial Disclosure: Nil.

Conflict of Interest: None declared.

\section{References}

1. Durski MT, Metz MJ, Crim GA. Tooth fragment reattachment and a class IV restoration: Case report. J Dent Oral Health Cosmesis 2016;1:002 doi:10.24966/DOHC-6783/100002

2. Yilmaz Y, Guler C, Sahin H, Eyuboglu O. Evaluation of tooth-fragment reattachment: A clinical and laboratory study. Dent Traumatol 2010;26(4):308-314 doi:10.1111/j.16009657.2010.00907.x

3. Shirani F, Malekipour MR, Tahririan D, Sakhaei Manesh V. Effect of storage environment on the bond strength of reattachment of crown fragments to fractured teeth. J Conserv Dent 2011;14(3):269-272 doi:10.4103/0972-0707.85813

4. Díaz JA. Crown fractures in maxillary central incisors; 24 months follow-up and clinical outcome in children. Int. J Odontostomat 2008;2(1):83-94

5. Garcia FCP, Poubel DLN, Almeida JCF, et al. Tooth fragment reattachment techniques-A systematic review. Dent Traumatol 2018;34(3):135-143 doi:10.1111/edt.12392

6. Coelho-de-Souza FH, Fossá G, Pereira FD, Klein-Júnior CA, Erhardt M, Thomé T. Fracture resistance of incisal tooth fragment reattached with different adhesive materials and retentive techniques. Rev Odonto Cienc 2017;32(4):163-168 doi:10.15448/1980-6523.2017.4.28095

7. Divakar HD, Nayak M, Shetty R. Changing concepts in fracture reattachment of teeth-A case series. Endodontology 2007;2:48-54

8. Adanir N, Belli S. Stress analysis of a maxillary central incisor restored with different posts. Eur J Dent 2007;1(2):67-71

9. Demarco FF, Fay RM, Pinzon LM, Powers JM. Fracture resistance of re-attached coronal fragments--influence of different adhesive materials and bevel preparation. Dent Traumatol 2004;20(3):157163 doi:10.1111/j.1600-4469.2004.00221.x

10. Patni P, Jain D, Goel G. A holistic approach to management of fractured teeth fragments: A case report. Oral Surg Oral Med Oral Pathol Oral Radiol Endod 2010;109(5):e70-e74 doi:10.1016/j.tripleo.2009.12.045

11. Nogueira Filho Gda R, Machion L, Teixeira FB, Pimenta LA, Sallum EA. Reattachment of an autogenous tooth fragment in a fracture with biologic width violation: a case report. Quintessence Int 2002;33(3):181-184

12. Macedo GV, Diaz PI, De O Fernandes CA, Ritter AV. Reattachment of anterior teeth fragments: a conservative approach. J Esthet Restor Dent 2008;20(1):5-20 doi:10.1111/ j.1708-8240.2008.00142.x

13. Martin W, Taylor C, Jawad S, Roudsari RV, Darcey J, Qualtrough A. Modern endodontic principles part 7: The restorative 
interface. Dent Update 2016;43(4):319-334 doi:10.12968/ denu.2016.43.4.319

14. Giovani AR, Vansan LP, de Sousa Neto MD, Paulino SM. In vitro fracture resistance of glass-fiber and cast metal posts with different lengths. J Prosthet Dent 2009;101(3):183-188 doi:10.1016/ S0022-3913(09)60025-1

15. Patnana AK, Vanga NRV. The clinical management of complicated crown root fractures: A Case report with literature review. IJSR 2018;7(2):32.33

16. Durkan RK, Ozel MB, Celik D, Bağiş B. The restoration of a maxillary central incisor fracture with the original crown fragment using a glass fiber-reinforced post: A clinical report. Dent Traumatol 2008;24(6):e71-e75 doi:10.1111/j.16009657.2008.00702.x

17. Taguchi CM, Bernardon JK, Zimmermann G, Baratieri LN. Tooth fragment reattachment: A case report. Oper Dent 2015;40(3):227-234 doi:10.2341/14-034-T

18. Adanir N, Belli S. Evaluation of different post lengths' effect on fracture resistance of a glass fiber post system. Eur J Dent 2008;2(1):23-28

19. Raut AW, Mantri V, Shambharkar VI, Mishra M. Management of complicated crown fracture by reattachment using fiber post: Mminimal intervention approach. J Nat Sci Biol Med 2018;9(1):93-96 doi:10.4103/jnsbm.JNSBM_98_17

20. Abdulkhayum A, Munjal S, Babaji P, et al. In-vitro evaluation of fracture strength recovery of reattached anterior fractured tooth fragment using different re-attachment techniques. J Clin Diagn Res 2014;8(3):208-211 doi:10.7860/JCDR/2014/7161.4164

21. Pusman E, Cehreli ZC, Altay N, Unver B, Saracbasi O, Ozgun G. Fracture resistance of tooth fragment reattachment: effects of different preparation techniques and adhesive materials. Dent Traumatol 2010;26(1):9-15 doi:10.1111/j.16009657.2009.00855.x

22. Reis A, Francci C, Loguercio AD, Carrilho MR, Rodriques Filho LE. Re-attachment of anterior fractured teeth: fracture strength using different techniques. Oper Dent 2001;26(3):287-294

23. Chazine M, Sedda M, Ounsi HF, Paragliola R, Ferrari M, Grandini $\mathrm{S}$. Evaluation of the fracture resistance of reattached incisal fragments using different materials and techniques. Dent Traumatol 2011;27(1):15-18 doi:10.1111/j.1600-9657.2010.00951.x

24. Sabatini C. Effect of phosphoric acid etching on the shear bond strength of two self-etch adhesives. J Appl Oral Sci 2013;21(1):5662 doi:10.1590/1678-7757201302370

25. Poubel DLN, Almeida JCF, Dias Ribeiro AP, Maia GB, Martinez JMG, Garcia FCP. Effect of dehydration and rehydration intervals on fracture resistance of reattached tooth fragments using a multimode adhesive. Dent Traumatol 2017;33(6):451-457 doi:10.1111/edt.12344

26. Goinka C, Priya BD, Korral BR, Priyadarshini I, Srinidhi VB, Kadiyala A. Immediate reattachment of anterior teeth fragments using prefrabricated post and composite: A conservative approach. GJRA 2018;6(7):15-17 